Teller, Christoph, Schnedlitz, Peter. Drivers of Agglomeration Effects in Retailing - the Shopping Mall Tenant's Perspective. Journal of Marketing Management, accepted, forthcoming.

Drivers of Agglomeration Effects in Retailing - the Shopping Mall Tenant's Perspective

Christoph Teller ${ }^{\mathrm{I}}$, Peter Schnedlitz ${ }^{\mathrm{II}}$

I, [corresponding author] Institute for Retail Studies, University of Stirling, Stirling. FK9

4LA. Scotland, United Kingdom. Tel: +44 (0) 1786 466454; Fax: +44 (0) 1786465290.

Email: christoph.teller@stir.ac.uk.

$\dagger \dagger$, Institute for Retailing and Marketing, Vienna University of Economics and Business,

Augasse 2-6, A-1090 Vienna, Tel: +43 (0)1 31336 4618; Fax: +43 (0)1 31336 717. Email:

peter.schnedlitz@wu.ac.at 


\title{
Drivers of Agglomeration Effects in Retailing - the Shopping Mall Tenant's Perspective
}

\begin{abstract}
Retail and service enterprises seek benefits and synergies from locating their stores within retail agglomerations, such as shopping streets and malls. The aim of this paper is to identify the main drivers of such synergetic or 'agglomeration effects' for tenants. A literature review reveals four sets of drivers that are related to the location, the tenant mix, the marketing and the management of an agglomeration. Based on a survey of 217 managers representing stores that are located in five regional and four supra-regional shopping malls, we demonstrate that location related drivers including geographical location, accessibility and parking conditions have a significant higher impact on agglomeration effects in terms of the economic success of tenants. The results were consistent amongst different types of tenants differentiated by store size, customer footfall, industry affiliation and perceived role within the respective mall (as footfall taker or generator within the network).
\end{abstract}

Keywords: Retail Agglomeration, Place Marketing, Shopping Centre, Centre Management

\section{Biographies}

Christoph Teller is a senior lecturer in marketing in the Institute for Retail Studies, Stirling Management School, University of Stirling. His research interests are in the area of store (format) and agglomeration (format) choice/patronage, retail logistics and web-based research methodologies.

Peter Schnedlitz is full professor and head of the Institute Retailing and Marketing at the Vienna University of Economics and Business. His research interests are in the area of retail marketing, consumer behaviour, retail logistics and operations. 


\section{Drivers of Agglomeration Effects in Retailing - the Shopping Mall Tenant's Perspective}

\section{Introduction}

A set of stores that offer goods and services to consumers and that are located and operated in close proximity to each other are denoted as retail agglomerations (Teller, 2008). The number of created retail agglomerations - such as shopping malls or any other kind of shopping centres - have increased substantially in the last few decades. Currently the number of shopping centres in Europe is approximately 5,700 whereas a further 80 centres are planned to be built by 2014 (schemes on hold are not included) (Anonymous, 2009a/b). More than $20 \%$ of all retail sales are generated and the same share of all retail employees work in such created store clusters (ICSC, 2009). Arguably, one of the main success factors of shopping centres is the centralised control of synergetic effects between agglomeration tenants from the planning to the operations stage in the form of a centre management (Howard, 1997). Compared to shopping centres, evolved agglomeration formats - in particular regional shopping streets and inner-city retail clusters - constantly lose market share (for an overview see e.g. Teller, 2008; Anonymous, 2009b). This is because of the lack of cooperation between tenants in terms of marketing and the absence of an agglomeration management in order to increase agglomeration effects (Warnaby et al., 2002; Bennison et al., 2005).

Traditionally, created agglomerations in particular shopping malls, have been in the focus of researchers from the disciplinary fields of geography, retailing and marketing (for an overview see e.g. Dennis et al., 2005; Guy, 2007; Teller \& Reutterer, 2008). Although interest in evolved formats - especially in the context of the growing competition with their created counterparts - has increased in recent years the question of how to influence the major benefits from locating retail businesses in close proximity to one another (i.e. agglomeration 
effects) remains widely neglected. Specifically, in the extant literature the generic nature of agglomerations - independent of their formats - and the rationale for this spatial gravitation of agglomerations from a tenant's point of view has received surprisingly little attention in literature.

Nelson (1958) was one of the first authors to focus on agglomeration effects. He refers to the 'cumulative attraction' store clusters and thus emphasised the advantages of spatial retail networks in contrast to scattered retail locations. Ghosh (1986), Oppewal \& Holyoake (2004) and Arentze et al. (2005) have examined agglomeration effects from the consumer's point of view and provide empirical evidence in terms of the superior importance of retail agglomerations for consumers' planning and undertaking of multi-purpose shopping trips. In contrast to that, Howard (1997) discussed the relationships of tenants in the form of conflicts and collaboration within shopping malls as a result of agglomeration effects. Similarly Prendergast (1998) tries to give an answer why retailers locate their outlets in shopping malls but can only give partial (empirical) insights into the importance and the drivers of agglomeration effects from a tenant's point of view. The most recent work on synergies between tenants of retail agglomerations is provided by Teller et al. (2008) who distinguish between different sub-dimensions of agglomeration effects that create benefits for consumers in shopping streets and shopping malls, empirically evaluating the relevance of these dimensions for hedonic and utilitarian shopper types. It can be concluded that the existing literature only provides partial insights into what actually drives agglomeration effects.

Nevertheless, the understanding of how stores interplay within business networks like agglomerations and how agglomeration effects can be utilised is of crucial importance for tenants and agglomeration management in retail markets where the intra- and inter-format competition has increased. To know what drives agglomeration effects most enables 
management to focus on and to prioritise those aspects and areas of agglomerations that have the greatest impact on the attractiveness for existing and potential consumers and tenants (Teller et al., 2008). The main drivers of agglomeration effects can thus be seen as sources for competitive advantages of agglomerations and thus the success of their tenants.

As a consequence, the aim of this paper is to identify the drivers of agglomeration effects and subsequently how agglomeration management can positively influence these synergies in order to increase the benefit of its tenants and customers respectively. By doing so we emphasise the tenant's view point because: (1) they represent the interface between agglomeration patrons and management and thus have an in-depth knowledge about 'their' retail agglomerations in general and the drivers of agglomeration effects in particular; (2) they can be seen as the key to the attractiveness and the success of an agglomeration (e.g. Teller \& Reutterer, 2008). The main contributions of this paper are to increase the understanding about what makes - and could make - retail agglomerations successful for retail and service organisations as a location for their stores and attractive for consumers as a shopping destination respectively. Thereby we endeavour to complement the consumer focused discussion of retail agglomerations with the supply-side view.

The paper is structured as follows: after these introductory comments, we characterise retail agglomerations as business networks generating synergetic effects for their tenants. Generic drivers of agglomeration effects are identified and propositions assuming the superior importance of each driver are set up. We then characterise the methodology of an empirical study designed to test our propositions. The results are consequently presented and discussed with respect to existing literature and practical implications. A limitation and outlook section concludes the paper. 


\section{Agglomeration effects and their drivers}

Retail agglomerations are business networks bound to a certain location. As such, stores, i.e. spatial representations of retail or service organisations, represent nodes and the relationships between these nodes correspond to threads (Hakansson \& Ford, 2002). This network view stresses the importance of not considering the relationship between stores independent and isolated from each other. The relationships - as a result of the close proximity to each other tie together nodes in retail agglomerations (Ghosh, 1986). The association of tenants can be described by being both cooperative and competitive (Howard, 1997). On one hand, tenants compete for the same (prospective) consumers and, on the other, they cooperate when using the same infrastructure, e.g. traffic system, parking facilities, signage, infrastructural services - i.e, traffic management, parking space control, cleaning, security service - and ultimately the footfall not necessarily generated by themselves (Howard, 1997).

This "co-opetition" (Brandenburger \& Nalebuff, 1996) between stores accounts for the most generic feature of such store networks and the rationale why organisations build such networks. As a result retail agglomerations form ‘quasi-organisations' (Ford et al., 1998). As such created retail agglomeration formats are centrally managed and marketed as single organisational entities (Teller \& Elms, 2010) whereas evolved agglomerations are branded and marketed by the involved retail and services businesses collaboratively with the aim of being perceived as single entities (Bennison et al., 2005).

Retail and service enterprises aim to benefit from so-called synergetic or "agglomeration effects" (Oppewal \& Holyoake, 2004) by being part of the network. Such effects either evolve naturally or - in addition - are generated and influenced deliberately by the nodes themselves or a separate managing or controlling unit that is part of the network (Teller et al., 2008). The 
aim of agglomeration managers, marketers and the organisations within the network is to influence agglomeration effects and thus the economic success of the stores and the agglomeration as a whole. Consequently, they influence agglomeration effects positively for consumers too (Arentze et al., 2005). Agglomeration effects can be defined as the benefits for tenants from being part of the network compared to being outside the network, e.g. those located in solitary locations. With regards to consumers, agglomeration effects are those benefits derived from using agglomerations as a (single) destination to satisfy a set of different wants and needs. Thus, every attribute of an agglomeration, and every measure taken by the organisations and the management that influences agglomeration effects, can be understood as a possible effect driver. This view would exclude all measures that are intended to increase the benefit of a single organisation exclusively. Nevertheless, due to the network characteristics of retail agglomerations even these measures and attributes of single stores can have an indirect effect on other tenants as well as the agglomeration as a whole. Different research streams dealing with retail agglomerations explicitly or implicitly consider drivers. From agglomeration related literature four sets of drivers can be identified:

(a) Location related drivers: Literature on retail planning and agglomeration patronage behaviour focuses on the drivers related to the location of retail agglomerations. This includes the geographical position of agglomerations and connection to the road network and/or public transportation system (Guy, 2007), the accessibility for consumers (Arentze \& Timmermans, 2001) and suppliers (Crainic et al., 2009), the availability of parking lots and costs of parking (Van der Waerden et al., 1998) and car-park routing systems and signage (Guy, 2007). These drivers are linked with the 'rationalisation effect' proposed by Teller et al. (2008) in terms of facilitating the shopping endeavours or logistics for consumers. 
(b) Tenants related drivers: Publications focusing on consumer behaviour in retail agglomerations emphasise the importance of tenant related drivers of agglomeration effects. These drivers account for the mix and attractiveness of retail stores (Chebat et al., 2010), the mix of bars, restaurants and other catering tenants (Reimers \& Clulow, 2004), the mix of entertainment facilities and service stores (Bloch et al., 1994). According to Teller et al. (2008) the "accumulation effect" and "enrichment effect" are affected by such drivers. The first effect denotes benefits for consumers who can carry out multi-purpose shopping trips due to the combined retail offer in agglomeration. The latter describes benefits generated by the augmentation of consumers' shopping trips in terms of the non-retail offer of an agglomeration which enables recreation, entertainment and social interaction with other people.

(c) Agglomeration marketing related drivers: The place marketing literature deals with this third set of drivers. It focuses on the cooperation of tenants when marketing a place to place user groups such as consumers, tourists and residents (Teller et al., 2010). Agglomeration tenants follow a supra-store marketing concept or agree on the application of marketing instruments in order to increase the attractiveness of the agglomeration as a shopping destination. The following drivers in terms of joint marketing activities fall under this category: joint communication efforts (Bennison et al., 2005), events in the agglomeration (Sands et al., 2009), measures to improve the agglomeration's atmosphere (Chebat et al., 2010) and the agglomeration's image (public relations) (Bennison et al., 2005), price promotions (Bennison et al., 2005), architecture, interior and decoration of the mall (Dennis et al., 2005; Turley \& Chebat, 2002), centralised marketing effort in general (Teller, 2008), market research efforts (Teller \& Elms, 2009), overall image and publicity of the agglomeration (Finn \& Louviere, 1996; Bennison et al., 2005). 
(d) Agglomeration management related drivers: The last set of drivers is related to the management of an agglomeration as a 'quasi organisation' by a centralised management unit - usually represented by the owner of the agglomeration property. These drivers are very specific for created retail agglomerations. The institutionalised management can be legitimised by contractual relationships with each tenant that empowers it to plan, coordinate, execute and control measures that increase the attractiveness for consumers and consequently the success for agglomeration and its tenants (Teller and Elms, 2009). This set of drivers includes measures or services provided by the central agglomeration management such as consistent opening hours (Baker, 2002), cleaning and security services (Severin et al., 2001; Bloch et al., 1994), public toilets (Baker et al., 2002), recreational areas for customers (Baker et al., 2002), central information counters (Reimers \& Clulow, 2004), signage within the mall and orientation system (Teller \& Reutterer, 2008), maintenance and improvement of the building structure (Hackett \& Foxall, 1994), consistent appearance of stores (Howard, 1997), arrangement of stores within the agglomeration (Wakefield \& Baker, 1998) and branding of the agglomeration (Dennis et al., 2005).

All four sets of drivers discussed above build upon each other. The location and tenant related drivers can be seen as generic for every kind of agglomeration format and are subject to the strategic planning decisions of agglomeration managers. The marketing and management related drivers can be understood as being of a higher order in the sense that they influence agglomeration effects by facilitating and optimising the agglomerations operations on a supratenant level. 


\section{Propositions}

The existence and strength of agglomeration effects are difficult to measure and the literature does not explicitly provide an approach to measure them. Authors focusing on agglomeration customers measure synergetic effects in agglomerations implicitly by evaluating the perception of agglomeration attributes, satisfaction, behavioural intentions or shopping behaviour (e.g. Oppewal \& Holyoake, 2004; Teller et al., 2008). A positive perception or behaviour in favour of an agglomeration relative to other retail locations can serve as indicators of the strength of agglomeration effects. Thus, tenants evaluate agglomeration effects by their economic success - i.e. sales and profit - that emerge because they are a part of the business network. Based on these thoughts we propose effects between the aforementioned set of drivers and the success of agglomeration tenants. The impact of each driver set on the economic success thus represents a measure to identify the most determinant factor of agglomeration effects.

The location related drivers have traditionally been the focus of retail and agglomeration researchers and been understood as crucial for the success of store based retailing in general (e.g. Reilly, 1931; Bellenger, 1977; Dennis et al., 2005). We therefore derive our first proposition:

$P_{1}$ : Location related drivers affect the success of agglomeration tenants significantly more than other drivers.

Teller \& Reutterer (2008) and Teller \& Elms (2010) present empirical evidence that the retail tenant mix is the major antecedent of agglomeration attractiveness from a consumer's point of view. In addition to that, the 'non-retail tenant mix' is seen as an additional driver by Reimers \& Clulow $(2004,2009)$. Consequently, we follow the notions of Nelson (1958) regarding the 
'cumulative attraction' of and Teller et al.'s (2008) discussion on the 'accumulation effect' in retail agglomerations and set up the following proposition:

$P_{2}$ : Tenant related drivers affect the success of agglomeration tenants significantly more than other drivers.

Howard (1997), Warnaby et al. (2002), Warnaby \& Medway (2004) and Bennison et al. (2005) and Teller and Elms (2010), identify the collaborative application of (place-) marketing instruments and concepts by agglomeration tenants as a core driver of the attractiveness of a place and consequently the success of its tenants. We therefore propose:

$P_{3}:$ The agglomeration marketing related drivers affect the success of agglomeration tenants significantly more than other drivers.

Whyatt (2004) and Teller (2008) consider the presence of an institutionalised management in an agglomeration as a crucial success factors within the competition of agglomeration formats. The argument is that a complex business network such as a retail agglomeration can be managed and marketed much more effectively and efficiently by a specialised and empowered central unit. Thus, the next proposition is:

$P_{4}:$ The agglomeration management related drivers affect the success of agglomeration tenants significantly more than other drivers.

According to Berman \& Evans (2010) tenants can play different roles within agglomerations. Depending on the size of the mall and the tenants in terms of space, customer frequency or industry affiliation, they can be seen as anchor stores attracting a considerable share of an agglomeration's customers or parasite stores that just profit from the footfall generated by 
other tenants. Due to their specific roles and characteristics within such spatial business networks, anchor tenants see different factors driving their success than parasites stores (Howard, 1997). As a consequence we derive our final proposition:

$P_{5}:$ Mall and tenant characteristics have a significant (moderating) impact on the relative importance of drivers for the success of agglomeration tenants (as proposed in $P_{1}-P_{4}$ ).

\section{Empirical study}

To investigate the relative impact of all identified agglomeration effect drivers we focused on shopping malls that have an institutionalised centre management. Store managers or store owners that are engaged in the daily retail or service business were selected as the informants and were consequently seen as those who have the most knowledge about and the best access to the required information about the proposed drivers. We drew a judgement sample of five regional shopping malls consisting of 17 to 47 stores and four supra-regional malls including 72-134 stores. In line with Teller (2008) we see supra-regional malls as being significantly bigger in size and offering more variety and assortment. They include more anchor tenants $(>2)$ and wider catchment area $(>30 \mathrm{~km})$ compared to regional malls. All malls represented in the sample are managed consistently by the biggest shopping centre owner in their respective central European retail market.

We conducted a web-based survey using self-administered and standardised questionnaires. The 570 targeted informants were pre-notified by the centre managers and the authors by mail and e-mail. During the survey period of two months two reminder letters and e-mails were sent out. Finally, we received 217 usable questionnaires which corresponded to a response rate of $38 \%$. By comparing all the tenants in the malls (i.e. population) with tenants 
represented by our respondents (i.e. sample) we could not identify a significant bias in terms of size or industry affiliation $\left(\chi_{(1)}^{2}<3.841 ; p>.5\right)$.

The stores represented by our respondents can be characterised as follows: Four out of five are retail stores and $34.5 \%$ of the included stores have a sales volume greater than EUR 600,000 per annum. Half of the stores are bigger than $120 \mathrm{~m}^{2}$ and have a footfall of 66 customers per day or more.

\section{Results}

\section{Factor analysis}

The respondents were confronted with 35 items operationalising the identified drivers of agglomeration effects as discussed above. They were asked to evaluate to what extent the drivers affect the success of their store within the agglomeration in terms of sales and profit. This was answered using a seven point rating scale ( 0 , absolutely not important for the success of my business/store; 6 , absolutely important for the success of my business/store).

In order to confirm the factor structure behind and to summarise the information contained in the items we conducted a principal component analysis (Hair et al., 2009). Although we distinguish between higher and lower order factors we find no evidence in literature that the derived factors should be treated as being (highly) correlated. We therefore used orthogonal factor rotation - more specifically varimax rotation. Compared to other rotation methods varimax facilitates a simple interpretation of factors by subsuming a smaller number of items under each factor (Hair et al., 2009). 
The Kaiser-Meyer-Olkin measured the adequacy of the sample for the analysis (KMO, .893; 'great'). On an item level, the KMO-values were greater than 0.753 and therefore above the recommended threshold of 0.5 . The correlation between the items was sufficiently large for a principal component analysis (Bartlett's test of sphericity $\left.\chi^{2}{ }_{(595)}, 5,218.18 ; \mathrm{p}<.001\right)$. In a first analysis attempt eight factors showed an eigenvalue greater than 1 (Kaiser's criterion). This set of factors explained $69.59 \%$ of the variance. The scree plot showed a clear point of inflexion after factor six (eigenvalue $>1.1$ ). Since the other two factors provide only marginal further explanation of variance the number of factors for the final analysis was retained at six. Almost all items show communalities higher than 0.5 (Hair et al., 2009). The only exceptions are items $\mathrm{x}_{110}, \mathrm{x}_{111}, \mathrm{x}_{26}$ and $\mathrm{x}_{27}$ with communalities slightly below the recommended cut-off value ( . 45; see appendix). Thus, we consider all our items as providing an acceptable level of explanation. Further all factor loadings prove to be significant. We therefore do not omit any of the 35 items from the analysis. The factor loadings after rotation can be seen from Table 1. 
Table 1: Extraction of factors

\begin{tabular}{|c|c|c|c|c|c|c|}
\hline \multirow[t]{2}{*}{ Factors } & \multicolumn{6}{|c|}{ Rotated factor loading } \\
\hline & $\begin{array}{l}\text { Agglomeration } \\
\text { marketing }\left(\xi_{1}\right)\end{array}$ & $\begin{array}{l}\text { (Infra-) Structural } \\
\text { characteristics }\left(\xi_{2}\right)\end{array}$ & $\begin{array}{c}\text { Facility } \\
\text { management }\left(\xi_{3}\right)\end{array}$ & $\begin{array}{l}\text { Tenant } \\
\operatorname{mix}\left(\xi_{4}\right)\end{array}$ & $\begin{array}{c}\text { Supply } \\
\text { conditions }\left(\xi_{5}\right)\end{array}$ & $\begin{array}{l}\text { Agglomeration } \\
\text { management }\left(\xi_{6}\right)\end{array}$ \\
\hline Joint events in the mall $\left(x_{11}\right)$ & .769 & & & & & \\
\hline Joint measures to improve the mall's image $(\mathrm{PR})\left(x_{12}\right)$ & .756 & & & & & \\
\hline Market research information (from centre mgmt) $\left(x_{13}\right)$ & .745 & & & & & \\
\hline Joint communication efforts $\left(x_{14}\right)$ & .744 & & & & & \\
\hline Overall publicity of the mall $\left(x_{15}\right)$ & 627 & & & & & \\
\hline Overall mall image $\left(x_{16}\right)$ & .623 & & & & & \\
\hline Interior and decoration of the mall $\left(x_{17}\right)$ & .583 & & & & & \\
\hline Joint price promotions $\left(x_{18}\right)$ & .549 & & & & & \\
\hline Centralised marketing of the mall $\left(x_{19}\right)$ & .539 & & & & & \\
\hline Joint measures to improve the mall's atmosphere $\left(x_{110}\right)$ & .518 & & & & & \\
\hline Architecture of the mall $\left(x_{111}\right)$ & .400 & & & & & \\
\hline Accessibility for customers $\left(x_{21}\right)$ & & .841 & & & & \\
\hline Number of parking spaces $\left(x_{22}\right)$ & & .727 & & & & \\
\hline Connection to the road network and/or public transport $\left(x_{23}\right)$ & & .696 & & & & \\
\hline No/low costs for customer parking $\left(x_{24}\right)$ & & .651 & & & & \\
\hline Geographical position of the mall $\left(x_{25}\right)$ & & .593 & & & & \\
\hline Consistent opening hours $\left(x_{26}\right)$ & & .472 & & & & \\
\hline Car-park routing system and signage $\left(x_{27}\right)$ & & .392 & & & & \\
\hline Cleaning services $\left(x_{31}\right)$ & & & .783 & & & \\
\hline Security services $\left(x_{32}\right)$ & & & .648 & & & \\
\hline Public toilets $\left(x_{33}\right)$ & & & .635 & & & \\
\hline Signage within the mall/orientation system $\left(x_{34}\right)$ & & & .628 & & & \\
\hline Maintenance/improvement of building structure $\left(x_{35}\right)$ & & & .550 & & & \\
\hline Recreational areas for customers $\left(x_{36}\right)$ & & & .522 & & & \\
\hline Arrangement of stores $\left(x_{37}\right)$ & & & .436 & & & \\
\hline Mix of bars, restaurants and other catering tenants $\left(x_{41}\right)$ & & & & .864 & & \\
\hline Mix of entertainment facilities and service stores $\left(x_{42}\right)$ & & & & .776 & & \\
\hline Mix of retail stores $\left(x_{43}\right)$ & & & & .739 & & \\
\hline Availability of attractive stores $\left(x_{44}\right)$ & & & & .537 & & \\
\hline Delivery conditions for suppliers $\left(x_{51}\right)$ & & & & & .869 & \\
\hline Accessibility of stores for suppliers $\left(x_{52}\right)$ & & & & & .868 & \\
\hline Consistent appearance of stores $\left(x_{61}\right)$ & & & & & & .647 \\
\hline Branding of the mall $\left(x_{62}\right)$ & & & & & & .559 \\
\hline Centralised management of the mall $\left(x_{63}\right)$ & & & & & & .491 \\
\hline Central information counters $\left(x_{64}\right)$ & & & & & & .471 \\
\hline Explained variance (\%; rotated sum of loadings): & 16.57 & 12,42 & 11.23 & 8.46 & 7,87 & 6.86 \\
\hline Cronbach $\alpha$ & .909 & .810 & .850 & .848 & .930 & .717 \\
\hline
\end{tabular}


The first of the six factors reflects the 'agglomeration marketing' related drivers $\left(\xi_{1}\right)$ and comprises a set of eleven marketing measures. The second factor represents '(infra) structural characteristics' $\left(\xi_{2}\right)$ of the shopping malls, including seven attributes that belong to 'location related drivers'. Surprisingly, the item 'consistent opening hours' is also subsumed under this factor and may therefore be understood as a measure of temporal accessibility compared to the other six measures for spatial accessibility. The next seven items are agglomeration management related and establish the factor 'facility management' $\left(\xi_{3}\right)$. This includes centrally managed activities like cleaning, maintenance and security services, and the provision of public toilets or signage. Factor four comprises four items that are denoted as 'tenant mix' related drivers $\left(\xi_{4}\right)$. Items describing the accessibility of the malls from the supplier's point of view are included in the factor 'supply conditions' $\left(\xi_{5}\right)$ of the agglomeration. The final and sixth factor 'agglomeration management' $\left(\xi_{6}\right)$ subsumes all management and branding related items. In total we see that both the agglomeration location and the management related drivers are represented by two factors each. The tenants and the agglomeration marketing related drivers are reflected in one factor exclusively.

\section{Calculation and comparison of impact index values}

To test our proposition, the impact of each factor in the form of an impact index value was calculated. This index value represents a weighted means that takes the various impacts of items towards each factor into consideration. Based on the notions of Johnson \& Gustaffson (2000) the factor score coefficients that were used in the principal component analysis served as weights after being divided by the standard deviation of each item. This was done in order to undo the standardisation and translate the weights back to their original scale. Based on the mean values $\mu_{\mathrm{xn}}$ and the weights $i_{\mathrm{xn}}$ of each item $\mathrm{x}_{\mathrm{n}}$ the impact index values (II) for factor $\xi_{\mathrm{m}}$ can be calculated as follows: 


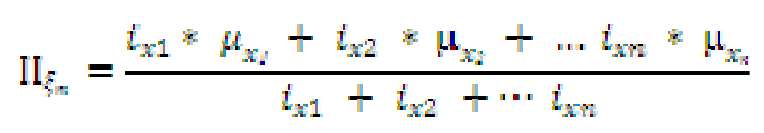

The actual values can be seen in the Appendix. Figure 1 provides a visual and Table 2 a statistical comparison (paired sample $t$-test) of the six impact index values.

Figure 1: Impact index values

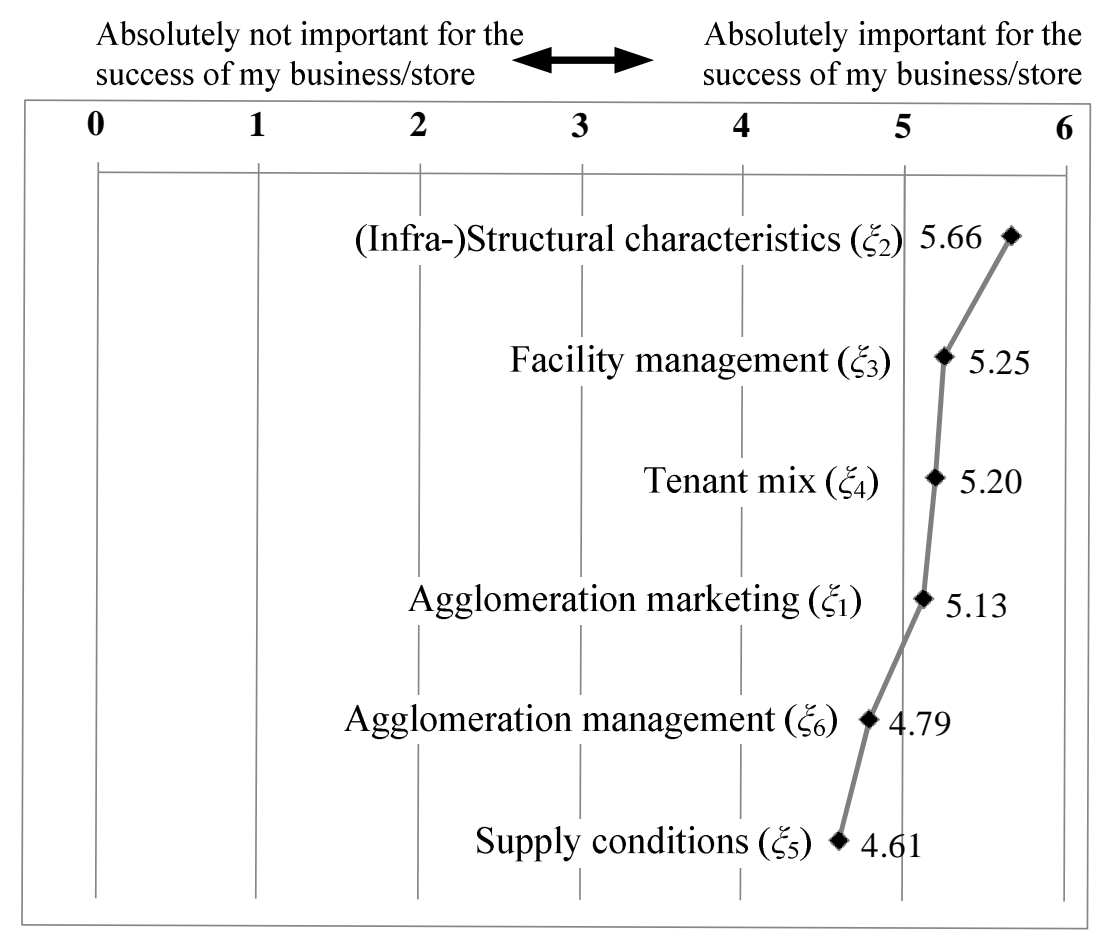

This shows that the second factor (infra-) structural characteristics $\left(\xi_{2}\right)$ has a significantly higher impact index value compared to all the other factors. The second highest values were identified for the factors facility management $\left(\xi_{3}\right)$, tenant mix $\left(\xi_{4}\right)$ and agglomeration marketing $\left(\xi_{1}\right)$ which are either not significantly different from each other or the significant difference is not substantial $(r<.1)$. Nevertheless, this set of factors shows significantly higher values compared to those of the factors agglomeration management $\left(\xi_{6}\right)$ and supply conditions $\left(\xi_{5}\right)$. This difference is slightly significant and the effect is not large and thus does not represent a substantial finding. Based on these results we can confirm proposition $\mathrm{P}_{1}$ and conclude that (infra-) structural characteristics and thus location related factors - apart from 
supply related drivers - contribute most to the success of agglomeration tenants within the malls investigated in this study. As a consequence, we cannot confirm propositions $\mathrm{P}_{2}$ to $\mathrm{P}_{4}$.

Table 2: Bivariate comparison of impact index values

\begin{tabular}{llllll}
\hline & $\xi_{1}$ & $\xi_{2}$ & $\xi_{3}$ & $\xi_{4}$ & $\xi_{5}$ \\
\hline$\xi_{1}$ & - & & & \\
$\xi_{2}$ & $t_{(216)},-10.84^{* * *}$ & - & & \\
& $r, .59$ & & & \\
$\xi_{3}$ & $t_{(216)},-2.70^{* *}$ & $t_{(216)}, 8.97^{* * *}$ & - & & \\
& $r, .18$ & $r, .52$ & & & \\
$\xi_{4}$ & $t_{(216)},-1.18^{\mathrm{ns}}$ & $t_{(216)}, 7.60^{* * *}$ & $t_{(216)}, .89^{\mathrm{ns}}$ & - & \\
& $r, .08$ & $r, .45$ & $r, .06$ & & \\
$\xi_{5}$ & $t_{(216)}, 5.03^{* * *}$ & $t_{(216)}, 10.66^{* * *}$ & $t_{(216)}, 6.38^{* * *}$ & $t_{(216)}, 5.16^{* * *}$ & - \\
& $r, .32$ & $r, .59$ & $r, .40$ & $r, .33$ & \\
$\xi_{6}$ & $t_{(216)}, 5.90^{* * *}$ & $t_{(216)}, 14.25^{* * *}$ & $t_{(216)}, 7.58^{* * *}$ & $t_{(216)}, 5.69^{* * *}$ & $t_{(216),-1.99^{*}}$ \\
& $r, .37$ & $r, .69$ & $r, .46$ & $r, .36$ & $r, .13$ \\
\hline
\end{tabular}

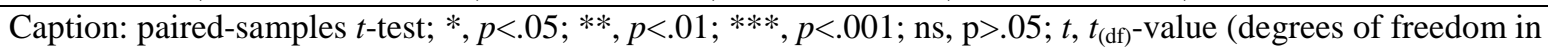
brackets); $r$, effect size;

\section{Moderating effects}

Being aware that our respondents represent reasonably heterogeneous set of tenants we compared the impact index values between subgroups. The potential moderators and the group splits are as follows:

- Mall size: Tenants in smaller malls (17 to 47 stores; $\mathrm{n}, 100) v s$. tenants in bigger malls (72 to 134 stores; n, 117)

- Industry affiliation: Retail tenants (n, 165) vs. non-retail tenants (n, 45)

- Store size: smaller tenants (floor space $<250 \mathrm{~m}^{2} ; \mathrm{n}, 143$ ) vs. bigger tenants (floor space $>249$ $\left.\mathrm{m}^{2} ; \mathrm{n}, 51\right)$

- Footfall: tenants with lower footfall ( $<200$ customers/day; n, 118) vs. tenants with higher footfall (>199 customers/day; n, 51) 
- Perceived role within the mall: footfall taker $(\mathrm{n}, 65) v s$. partial footfall generator $(\mathrm{n}, 152)$

By applying independent $t$-tests we identified no significant difference ( $p>.05)$ between any of the group splits. As a result we see that none of the above variables have a moderating effect on the impact index values. Consequently, proposition $\mathrm{P}_{5}$ cannot be confirmed.

\section{Discussion}

The impact index values for the six factors operationalising the four sets of agglomeration effect drivers are considerably high $(>4.1)$. Thus all indicators and consequently factors are seen to play a substantial role in influencing the success of the tenants. Consequently, we see as a major result that retail agglomerations - in these study shopping malls - generate agglomeration effects from their tenants' point of view. Since most of the agglomeration marketing and management drivers are very specific for the agglomeration format under investigation this overall result also explains the reasons for the increasing preference of retail and service organisations for shopping malls as locations for their stores (Teller \& Elms, 2009). Furthermore, this provides insights into why the number of malls is steadily increasing and their market share is rising compared to other agglomeration formats.

Nevertheless, when comparing the impact index values the results clearly show the significant and substantial importance of (infra-) structural characteristics of a shopping mall - such as the geographical location, the accessibility and parking conditions - as the main drivers of the success of the surveyed tenants. This finding can be confirmed for tenants in different mall types, of different size, with different customer footfall and different roles in the malls (parasite vs. anchors). Consequently, we can confirm the notions of e.g. van der Waerden $e t$ al. (1998), Oppewal \& Holyoake (2004) and Arentze et al. (2005) from the tenant's perspective. 
The facility management within the mall including cleaning, security, maintenance services and the provision of public toilets and recreational areas for consumers turned out to be the second most important driver. This finding is in line with Reimers \& Clulow's $(2004,2009)$ opinion of the superior importance of the convenience related attributes in shopping malls for consumers. Nevertheless, both core drivers prove to be of no importance in the work of Teller and colleagues (Teller et al., 2008; Teller \& Reutterer, 2008; Teller \& Elms, 2010), whose findings are based on the results consumer surveys in various agglomeration format settings. Since evolved retail agglomerations mostly lack the provision of such services this can be seen as a competitive disadvantage of shopping streets and inner-city retail clusters in order to attract tenants compared to created agglomeration formats.

The third most important driver proves to be the retail and non-retail tenant mix and thus indicates the importance of the 'cumulative attraction' of agglomerations for the success of their tenants (Nelson, 1958). This confirms the empirical finding from Teller's work but in this study confirmed from the tenant's point of view. Like the location of agglomerations, the correct and attractive mix of tenants is therefore considered as a decisive factor in the competition of retail agglomerations independent of format.

According to Warnaby et al. (2002), Bennison et al. (2005) and Teller et al. (2010) the agglomeration marketing efforts of tenants and a central agglomeration management - such as the application of communication, pricing or visual merchandising instruments - are key in increasing the success of tenants. Nevertheless, our results show that the collaborative place marketing endeavours are rated significantly lower than the first three sets of factors.

Another major finding is that an (institutionalised) agglomeration management is not considered as a major antecedent for the tenants' success. Thus, our study does not confirm 
the notions of, for example, Howard (1997). This proves to be interesting because the extant agglomeration literature considers a centralised and powerful management of an agglomeration in general, and a shopping mall in particular, is seen to be key for the success of an agglomeration and their tenants respectively (e.g. Teller and Elms, 2009). Furthermore, the supply conditions show significantly lower impact index values than all the other four. This disconfirms the findings of Crainic et al. (2009) and consequently indicates that the respondents do not see logistics costs and services attached to making the products available within the agglomerations as relevant for their success.

\section{Managerial implications}

From the management point of view our findings clearly show that retail agglomeration should be comprehended as being more than the sum of its parts, i.e. tenants. In other terms the success of an agglomeration and each tenant is closely tied together. By interpreting the item weights $\left(i_{\mathrm{xn}}\right)$ and the mean values $\left(\mu_{\mathrm{xn}}\right)$ of the ratings per item we can identify those drivers which should be targeted by the agglomeration management or the tenants in order to maximise the agglomeration effects, the success and competitiveness of the agglomeration and its tenants.

The agglomeration management should primarily emphasise the provision of the most appropriate environment for both tenants and consumers. Above all this includes the facilitation of an easy accessibility and the optimisation of parking facilities. Furthermore facility management issues - in particular cleaning and security services - should be a key concern. Besides that, it is crucial to optimise the right mix of retail and non-retail tenants and consequently increasing the co-opetition between them. The misconception about anchor tenants being the main and only driver of the success and thus representing a host to smaller 
tenants being parasites of agglomerations has to be resolved. Agglomeration management should therefore take into account the different roles of tenants within the network, e.g. in terms of tenants building up consumer traffic, reinforcing the brand of the agglomeration, providing a service to consumers, generating excitement for consumers or representing a core destination for consumers.

From a tenant's point of view, our findings suggest applying stronger 'network thinking' rather than 'silo or free rider thinking'. In terms of the most influencing drivers that can be controlled by tenants it turns out to be crucial to adapt and participate into cooperative marketing efforts since they are considered to result into benefits for the agglomeration as a whole and consequently the tenants. In particular, the organisation of joint events, joint public relations and advertising efforts should be prioritised. For small and medium size enterprises in most cases the majority of tenants - where marketing expertise is not highly developed, cooperative marketing through the agglomeration makes it possible to promote single and multiple stores efficiently and effectively.

\section{Limitations and future research agenda}

It should be mentioned that the empirical setting of this study is inevitably reflective of a European shopping mall environment. Consequently the results may not be generalisable, e.g. in a North American agglomeration context. The deliberate choice of the most important created agglomeration format - i.e. shopping mall - can be seen as another limitation. As a consequence the research design could be replicated in other geographical and agglomeration format settings such as other types of shopping centres but also high streets or town centres. This would reveal for example the potential of (urban) place marketing efforts for the success of evolved agglomerations from the tenant's point of view. 
Due to the focus of this paper the drivers of agglomeration effects were analysed and discussed mainly on an aggregated level. Nevertheless, the importance of each item within the determinant factors could be investigated and discussed in more depth. This would allow a more detailed view on what drives the success of tenants in the shopping malls investigated.

The discussion section has revealed contradictions in terms of the role of the two most important factors for tenants compared to consumers. In a next step tenants could be asked to evaluate 'their' agglomerations from the consumer's point of view. This will allow a richer insight into whether the literature suffers from a 'convenience myopia' (Teller, 2008) in terms of agglomerations - i.e. an exaggerated consideration of service elements included in the facility management factor.

\section{References}

Anonymous (2009a). Market overview and vital statistics. Centre Retailing, 67-83.

Anonymous (2009b). Building the future of retail. Retail Week, 10, 22-23.

Arentze T. A., \& Timmermans, H.J.P. (2001). Deriving performance indicators from models of multipurpose shopping behavior. Journal of Retailing and Consumer Services, 8, 325334.

Arentze, T.A., Oppewal, H., \& Timmermans, H.J.P. (2005). A multipurpose shopping trip model to assess retail agglomeration effects. Journal of Marketing Research, 42, 109115 .

Bellenger, D. N. (1977). Shopping center patronage motives. Journal of Retailing, 53, 29-38.

Bennison, D.J., Warnaby, G., \& Davies, B.J. (2005). Retailing and the marketing of urban places: a UK perspective. The International Review of Retail Distribution and Consumer Research, 15, 191-215.

Berman, B., \& Evans, J.R. (2010). Retail Management. A strategic approach. Upper Saddle River, NJ: Pearson Prentice Hall. 
Bloch, P.H., Ridgway, N.M., Dawson, S.A. (1994). The shopping mall as consumer habitat. Journal of Retailing, 70, 23-42.

Brandenburger, A., \& Nalebuff, B. (1996). Co-opetition, New York: Doubleday.

Chebat, J.C., Sirgy, M.J., \& Grzeskowiak, S. (2010). How can shopping mall management best capture mall image? Journal of Business Research, 63, 735-740.

Crainic, T.G., Ricciardi, N., \& Storchi, G. (2009). Models for evaluating and planning city logistics systems. Transportation Science, 43, 432-454.

Dennis, C., Marsland, D., \& Newman, A. (2005). Objects of Desire: Consumer Behaviour in Shopping Centre Choices. Hampshire/New York: Palgrave MacMillan.

Finn, A., \& Louviere, J.J. (1996). Shopping center image, consideration, and choice: anchor store contribution. Journal of Business Research, 35, 241-251.

Ford, D., Gadde, L-E., Hakansson, H., Lundgren, A., Snehota, I., Turnbull, P., \& Wilson D. (1998). Managing business relationships. London: Wiley.

Ghosh, A. (1986). The value of a mall and other insights from a revised central place model. Journal of Retailing, 62, 79-97.

Guy, C. (2007). Planning for Retail Development. A Critical View of the British Experience. London, New York, Routledge.

Hackett, P.M.W., \& Foxall, G.R.A. (1994). Factor analytic study of consumers' location specific values: a traditional high street and a modern shopping mall. Journal of Marketing Management, 10, 163-178.

Hair, J. F., Black, W. C., Babin, B. J., \& Anderson, R. E. (2009). Multivariate Data Analysis, Upper Saddle River, New Jersey: Prentice Hall.

Hakansson H., \& Ford, D. (2002). How should companies interact in business networks? Journal of Business Research, 55, 133-139.

Howard, E. (1997). The Management of shopping centres: conflict or collaboration? International Review of Retail, Distribution and Consumer Research, 7, 263-285.

ICSC (International Council of Shopping Centers) (2009). The Importance of Shopping Centres to the European Economy. Online: http://www.icsc.org/web/ EuropeanSummary.pdf.

Johnson, M. D. \& Gustafsson, A. (2000). Improving Customer Satisfaction, Loyalty and Profit. San Francisco, CA: Jossey-Bass. 
Nelson, R.L. (1958). The Selection of Retail Locations. New York: F.W. Dodge Corporation.

Oppewal, H., \& Holyoake, B. (2004). Bundling and retail agglomeration effects on shopping behaviour. Journal of Retailing and Consumer Services, 11, 61-74.

Prendergast, G., Marr, N., \& Jaratt, B. (1998). Retailers' views of shopping centres: a comparison of tenants and non-tenants. International Journal of Retail and Distribution Management, 26, 162-171.

Reilly, W. J. (1931). The Law of Retail Gravitation. New York.

Reimers, V., \& Clulow, V. (2004). Retail concentration: a comparison of spatial convenience in shopping strips and shopping centres. Journal of Retailing and Consumer Services, 11, 207-221.

Reimers, V., and Clulow, V. (2009). Retail centres: it s time to make them convenient. International Journal of Retail and Distribution Management, 37, 541-562.

Sands, S., Oppewal, H., \& Beverland, M. (2009). The effects of in-store themed events on consumer store choice decisions. Journal of Retailing \& Consumer Services, 16, 386-395.

Severin, V. (2001). The stability of retail shopping choices over time and across countries. Journal of Retailing, 77, 185-202.

Teller C., \& Elms, J. R. (2009). Managing the attractiveness of evolved and created retail agglomeration formats. Marketing Intelligence \& Planning, 28, 25-45.

Teller, C. (2008). Shopping streets versus shopping malls - determinants of agglomeration format attractiveness from the consumers' point of view. International Review of Retail, Distribution and Consumer Research, 18, 381-403.

Teller, C., \& Elms, J. R. (2010). Urban place marketing and retail agglomeration customers. Journal of Marketing Management, in print, DOI: 10.1080/0267257X.2010.517710.

Teller, C., \& Reutterer, T. (2008). The evolving concept of retail attractiveness: what makes retail agglomerations attractive when customers shop at them?" Journal of Retailing and Consumer Services, 15, 127-143.

Teller, C., Elms, J. R., Thomson, J. A., Paddison, A. R. (2010). Place marketing and urban retail agglomerations: an examination of shoppers place attractiveness perceptions. Journal of Place Branding and Public Diplomacy, 6, 124-133.

Teller, C., Reutterer, T., \& Schnedlitz, P. (2008). Hedonic and utilitarian shopper types in evolved and created retail agglomerations. International Review of Retail, Distribution and Consumer Research, 18, 283-309. 
Turley L. W., Chebat, J.C. (2002). Linking retail strategy, atmospheric design and shopping behaviour. Journal of Marketing Management, 18, 125-144.

Van der Waerden, P., Borgers, A., \& Timmermans, H. (1998). The impact of the parking situation in shopping centres on store choice behaviour. GeoJournal, 45, 309-315.

Wakefield, K.L., \& Baker, J. (1998). Excitement at the mall: determinants and effects on shopping response. Journal of Retailing, 74, 515-539.

Warnaby, G., \& Medway, D. (2004). The role of place marketing as a competitive response by town centres to out-of-town retail developments. International Review of Retail, Distribution and Consumer Research, 14, 457-477.

Warnaby, G., Bennison, D., Davies, B.J., \& Hughes, H. (2002). Marketing UK towns and cities as shopping destinations. Journal of Marketing Management, 18, 877-904.

Whyatt, G. (2004). Town centre management: how theory informs a strategic approach. International Journal of Retail and Distribution Management, 32, 346-353. 


\section{Appendix}

\begin{tabular}{|c|c|c|c|c|c|c|}
\hline Item & Communalities & $\begin{array}{l}\text { Factor score } \\
\text { weight }\left(\beta_{\mathrm{xn}}\right)\end{array}$ & $\begin{array}{c}\text { Standard } \\
\text { deviation }\left(\sigma_{\mathrm{xn}}\right)\end{array}$ & $\begin{array}{c}\text { Item weight } \\
\left(i_{\mathrm{xn}}\right)\end{array}$ & $\begin{array}{c}\text { Mean value } \\
\left(\mu_{\mathrm{xn}}\right)\end{array}$ & $\begin{array}{c}\text { Impact index } \\
\text { value }\left(\mathrm{II}_{\xi \mathrm{m}}\right)\end{array}$ \\
\hline$x_{11}$ & .611 & 0.27 & 1.19 & 0.23 & 5.10 & 5.13 \\
\hline$x_{12}$ & .755 & 0.20 & 1.04 & 0.19 & 5.30 & \\
\hline$x_{13}$ & .669 & 0.22 & 1.46 & 0.15 & 4.65 & \\
\hline$x_{14}$ & .707 & 0.22 & 1.12 & 0.20 & 5.06 & \\
\hline$x_{15}$ & .655 & 0.14 & 0.79 & 0.18 & 5.59 & \\
\hline$x_{16}$ & .754 & 0.11 & 0.81 & 0.13 & 5.54 & \\
\hline$x_{17}$ & .581 & 0.12 & 1.12 & 0.11 & 5.19 & \\
\hline$x_{18}$ & .646 & 0.16 & 1.45 & 0.11 & 4.35 & \\
\hline$x_{19}$ & .690 & 0.06 & 1.11 & 0.06 & 5.19 & \\
\hline$x_{110}$ & .468 & 0.11 & 1.14 & 0.09 & 5.24 & \\
\hline$x_{111}$ & .425 & 0.09 & 1.17 & 0.08 & 4.97 & \\
\hline$x_{21}$ & .766 & 0.30 & 0.57 & 0.52 & 5.77 & 5.66 \\
\hline$x_{22}$ & .594 & 0.25 & 0.76 & 0.33 & 5.62 & \\
\hline$x_{23}$ & .627 & 0.22 & 0.75 & 0.29 & 5.65 & \\
\hline$x_{24}$ & .500 & 0.23 & 0.57 & 0.40 & 5.82 & \\
\hline$x_{25}$ & .568 & 0.17 & 0.83 & 0.21 & 5.53 & \\
\hline$x_{26}$ & .400 & 0.17 & 1.31 & 0.13 & 5.29 & \\
\hline$x_{27}$ & .434 & 0.07 & 1.02 & 0.07 & 5.29 & \\
\hline$x_{31}$ & .693 & 0.37 & 0.82 & 0.45 & 5.59 & 5.25 \\
\hline$x_{32}$ & .658 & 0.27 & 1.14 & 0.23 & 5.10 & \\
\hline$x_{33}$ & .664 & 0.24 & 1.07 & 0.22 & 5.27 & \\
\hline$x_{34}$ & .633 & 0.23 & 1.04 & 0.22 & 5.22 & \\
\hline$x_{35}$ & .514 & 0.24 & 1.35 & 0.18 & 4.93 & \\
\hline$x_{36}$ & .563 & 0.18 & 1.30 & 0.14 & 4.84 & \\
\hline$x_{37}$ & .524 & 0.11 & 1.00 & 0.11 & 5.27 & \\
\hline$x_{41}$ & .778 & 0.44 & 1.19 & 0.37 & 5.15 & 5.20 \\
\hline$x_{42}$ & .745 & 0.36 & 1.41 & 0.26 & 4.72 & \\
\hline$x_{43}$ & .755 & 0.32 & 1.01 & 0.32 & 5.42 & \\
\hline$x_{44}$ & .696 & 0.19 & 0.91 & 0.21 & 5.52 & \\
\hline$x_{51}$ & .855 & 0.37 & 1.60 & 0.23 & 4.53 & 4.61 \\
\hline$x_{52}$ & .827 & 0.38 & 1.61 & 0.23 & 4.68 & \\
\hline$x_{61}$ & .625 & 0.38 & 1.68 & 0.22 & 3.98 & 4.79 \\
\hline$x_{62}$ & .601 & 0.28 & 1.23 & 0.23 & 5.03 & \\
\hline$x_{63}$ & .638 & 0.21 & 1.14 & 0.19 & 5.16 & \\
\hline$x_{64}$ & .616 & 0.19 & 1.09 & 0.18 & 5.12 & \\
\hline
\end{tabular}

